\title{
Paradiplomacia nas Relações Internacionais: a importância da cultura como elemento transformador do cenário político internacional
}

\author{
Paradiplomacy in International Relations: the importance of culture as a \\ transforming element in the international political scene
}
Nikolas Yoshitaka Konishi ${ }^{1}$; Alice Pillo de Mendonça²; Dra. Maria de Fátima Bento
Ribeiro $^{3}$;

${ }^{1}$ nikonishi@gmail.com, Universidade Federal de Pelotas; ${ }^{2}$ pilloalice@ gmail.com, Universidade Federal de Pelotas; ${ }^{3}$ mfabento@ hotmail.com, Universidade Federal de Pelotas.

\begin{abstract}
Resumo
O presente artigo possui como objetivo apresentar uma perspectiva das relações internacionais onde novos atores adentram aos processos diplomáticos, até então exclusivos das interações entre Estados-Nação. Na paradiplomacia, o Subnacional (regiões, estados federais e municípios), organizações e sociedade civil começam a dividir espaços antes restritos às governanças, auxiliando o desenvolvimento de políticas públicas. Com a crescente relevância dos estudos conceituais sobre Cultura, demonstra-se cada vez mais o papel importante que esta desempenha nas relações exteriores. Assim sendo, este trabalho terá como objetivo compreender as ações paradiplomáticas e qual a relevância da Cultura, em conjunto com a Teoria das Relações Internacionais, como instrumento de desenvolvimento para estas políticas. Observaremos ações políticas que ocorrem na zona de fronteira entre Brasil e Uruguai, para identificar as ações paradiplomáticas existentes.
\end{abstract}

Palavras-chave: Paradiplomacia; Cultura; Teoria das Relações Internacionais; Interdependência; Subnacional; Brasil; Uruguai.

\begin{abstract}
This paper aims to provide a perspective of the international relations in which new players step into the diplomatic process, that so far were unique interactions between Nation States. In the paradiplomacy, the "SubNational" (regions, federal states and municipalities), organizations and civil society start to share a space previously restricted to governances, helping the development of public policies. With the increasing relevance of conceptual studies on Culture, it's easy to note the important role it plays in foreign affairs. Therefore, this work will aim to comprehend the paradiplomatic actions and the relevance of Culture, along with the International Relations Theory, as a development tool for these policies. Besides this, there's a need to observe political actions that occur in the border area between Brazil and Uruguay to identify existing paradiplomatic actions.
\end{abstract}

Key-words: Paradiplomacy; Culture; International Relations Theory; Interdependence; Subnational; Brazil; Uruguay. 


\section{Introdução}

Este trabalho tem como objetivo discutir a paradiplomacia ${ }^{1}$, utilizando a cultura como instrumento diplomático. Dentro deste âmbito, busca-se entender o conceito e a finalidade diplomática, por meio da ótica das teorias das Relações Internacionais, identificando outros estudos que auxiliam e qualificam a percepção do conhecimento em pauta.

Com o progresso da globalização, o surgimento de novos atores, ao decorrer do século XX, gera dúvidas para questões de soberania. Até então, somente o Estado-Nação deveria ser possuidor de personalidade internacional, visto que tinha existência exclusiva nas maiores instâncias políticas e econômicas que regiam o mundo. Concomitantemente, também pelo advento dos fenômenos da globalização e suas tecnologias, observa-se crescentes movimentos transnacionais ${ }^{2}$, subnacionais, não-governamentais, atuação da sociedade civil, de integração regional e de cooperação, que estão cada vez mais fortes.

O trabalho parte também do pressuposto de que essas novas forças, que alguns apontam como causas de uma crise do Estado-Nação, não são de fato prejudiciais para a estrutura existente, e sim, caso organizadas e incorporadas com inteligência pelos governos, possuem o poder de catalisar o desenvolvimento.

$\mathrm{O}$ assunto em questão ainda ganha mais importância em países com dimensões continentais como o Brasil. Onde o espaço territorial, zonas de fronteira, linhas de fronteira, fronteira marítimas, espaço aéreo e quantidade de vizinhos, desafiam a logística da segurança e desenvolvimento da máquina pública. Portanto, a especialização das unidades, orquestradas por uma inteligência, acaba tendo uma estratégia mais lógica do que a especialização e centralidade do poder em uma única região.

No que diz respeito à metodologia, foram utilizadas obras no campo das Teorias das Relações Internacionais, procurando identificar os processos e a relevância da temática na paradiplomacia. Busca-se, assim, entender a estrutura e instrumentalização desta. Paralelamente, há a hipótese de que o estudo conceitual em cultura é o alimento fundamental para o desenvolvimento qualitativo desta forma de diplomacia. Paralelamente, temos a hipótese de que o estudo conceitual em cultura é o alimento fundamental para o

\footnotetext{
${ }^{1}$ Relações diplomáticas realizadas por entes subnacionais.

${ }^{2}$ Movimentos que vão além das fronteiras nacionais, englobando mais de uma nação.
} 
desenvolvimento qualitativo desta forma de diplomacia. Atualmente, a cultura é o principal foco de consagrados pensadores contemporâneos ${ }^{3}$.

O presente trabalho ainda tem o intuito de mostrar que, por meio das instituições, a população pode ser sensibilizada para a preservação e resgate do patrimônio cultural fronteiriço.

\section{Paradiplomacia, Relações Internacionais e Cultura}

\subsection{O Estudo das Relações Internacionais}

$\mathrm{O}$ estudo científico das Relações Internacionais ${ }^{4}$, possuidor de uma característica multidisciplinar, permite uma plataforma de utilização de vários eixos do conhecimento. Desta forma, facilita o entendimento estrutural e de interligação da ciência de distintas naturezas.

No Brasil, o estudo acadêmico insere-se formalmente com a criação do curso de graduação em bacharelado, na $\mathrm{UnB}^{5}$, em 1974. 10 anos depois, inicia-se também o primeiro curso de mestrado. Houve um maior crescimento dos centros de ensino e pesquisa em RI(REL) ${ }^{6}$ pós 1990. De acordo com a Federação Nacional dos Estudantes de Relações Internacionais, existem cerca de 93 faculdades e universidades brasileiras que oferecem o curso. $^{7}$

No cenário internacional, reporta-se, em 1920, pós Primeira Guerra Mundial, o pioneirismo do domínio teórico ao Royal Institute of International Affairs e, concomitantemente, à instituição London School of Economics. Contudo, mesmo como um período razoável para a exploração acadêmica, a maioria das produções cientificas estão ligadas às experiências empíricas Européias e Norte-Americanas. Não correspondendo aos

\footnotetext{
${ }^{3}$ Como sabemos, para a antropologia cultura é a soma de hábitos, costumes e realizações de um indivíduo, uma comunidade, um povo, ao longo de sua história. Essas realizações, por sua vez, cobrem todos os campos da atividade humana, das artes à ciência, da tecnologia ao folclore, da política à religião, da saúde ao esporte, do comércio ao lazer. A opção por uma definição abrangente fundamenta-se no pensamento de que a suprema manifestação de uma sociedade é a forma como ela vive, seus hábitos e costumes, e seu legado para as gerações que seguem. É ante esse plano geral mais amplo que deve ser colocado o primeiro plano da diplomacia cultural. (RIBEIRO, E. 2011)

${ }^{4}$ No presente artigo será adotado "Relações Internacionais" com as iniciais maiúsculas para definir o estudo da área.

${ }^{5}$ Universidade de Brasília.

${ }^{6}$ Diferentes regiões e/ou centros de ensino adotam R.I. ou R.E.L como sigla para a área de estudo das Relações Internacionais no Brasil.

${ }^{7}$ Lista disponível no endereço virtual da Federação Nacional dos Estudantes de Relações Internacionais:

Disponível em < http://www.feneri.org.br/feneri/faculdades >. Acesso em: 05 de outubro de 2014.
} 
processos históricos e diplomáticos Latino-Americanos, Sul-americanos, Mercosulinos e Brasileiros:

\begin{abstract}
A produção científica brasileira na área de RI, embora significativa, reflete interesses individuais e por isso tende a ser fragmentada, sendo praticamente inexistente a produção para fins didáticos, voltada especificamente para a formação de alunos de RI. Essa situação obriga professores e alunos a recorrerem a material editado no exterior, quase sempre em inglês, obviamente mais adequado para os países de origem (GUIMARÃES, 2001, p.5).
\end{abstract}

Aproveitando a localidade da Universidade Federal de Pelotas ${ }^{8}$, em mesma faixa de fronteira $^{9}$, este artigo utilizará o estudo das Teorias de Relações Internacionais e a conceituação de Cultura a fim de destacar a paradiplomacia experimentada nesta faixa, entre Brasil e Uruguai. Nesse âmbito, leva-se em conta a experiência do contexto histórico e diplomático regional.

A fronteira é o limite entre duas partes (dois Estados, dois estados federativos ou dois municípios); enquanto que a linha de fronteira é o limite geográfico das entidades políticas ou jurisdições. Já a faixa de fronteira, de acordo com o IBGE:

\begin{abstract}
Cadastro dos municípios brasileiros com área total ou parcialmente localizada na Faixa de Fronteira, que é a faixa interna de $150 \mathrm{~km}$ de largura, paralela à linha divisória terrestre do território nacional, agregando as informações existentes (código geográfico e nome do município) com as produzidas na identificação e/ou classificação do município dentro da faixa, tais como: fronteiriço, parcial ou totalmente na faixa, referências da sede a linha de fronteira e ao limite da faixa interna. ${ }^{10}$ OBJETIVOS: a finalidade principal é a identificação das unidades político-administrativas do Brasil localizadas na Faixa de Fronteira que estão sob regras de segurança nacional, em especial, no tocante a obras públicas de engenharia civil, participação de estrangeiros em propriedades rurais ou empresas nestas áreas, concessões de terras e serviços e auxílio financeiro do governo federal; secundariamente, no tocante a gratificação especial de localidade. ${ }^{11}$
\end{abstract}

O entendimento da cultura produzida na fronteira permite compreender que os limites físicos da geografia são construídos em um imaginário. Segundo Maria Eunice Moreira (1989), as características que causam uma separação geográfica entre os territórios não são sentidas pelas personagens que os observam apenas como terra, onde se mesclam costumes e pronúncias.

“Aqui há uma terra só, só há uma gente, seja do lado de cá, seja do lado de lá" (SCHLEE, 1984, p. 6). O trecho da obra "Uma terra só" de Aldyr Garcia Schlee faz-se

\footnotetext{
${ }^{8}$ O Bacharelado em Relações Internacionais da UFPel iniciou suas atividade em 2010.

${ }^{9}$ A distancia de condução entre Pelotas e Jaguarão é de $139 \mathrm{~km}$.

${ }^{10}$ Lei n ${ }^{\circ}$ 6.634, de 02/05/79, regulamentada pelo Decreto no 85.064, de 26/08/80; Instruções da Secretária-Geral do Conselho Nacional, de 28/07/81. Fonte: IBGE, Disponível em <http://www.ibge.gov.br/home/geociencias/geografia/fronteira.shtm?c=3>. Acesso em: 25 de outubro de 2014 . ${ }^{11}$ Ibdem.
} 
importante ao levantar a questão de fronteira como uma região que possibilita a união de culturas, formando uma identidade única.

A experiência da faixa de fronteira do Rio Grande do Sul com o Uruguai é única, não por simplesmente ser uma fronteira, mas por toda sua singularidade, do compartilhamento de processos de formação social, político, econômico, artístico e histórico. Enquanto, ao redor do globo, outros exemplos de fronteira desenvolvem-se em situação de constante conflito; a região do pampa sensivelmente vive em paz $^{12}$.

Existe na relação fronteiriça, então, uma importância local e interesse empírico, para as produções científicas nacionais em Relações Internacionais. "Todos os lugares são construções metafóricas, mas enquanto algumas não necessitam ser justificadas, outras o necessitam, pois são como planetas sem boca” (ACHUGAR, 2006, p. 22).

\subsection{Teoria das Relações Internacionais e Cultura}

Para definir níveis de análise e introduzir maior rigor científico no campo teórico das relações internacionais, a publicação de Waltz (1979), sobre teoria, torna amplamente conhecida duas abordagens: a reducionista e a sistêmica. De acordo com Buzan, citado por Guimarães (2001):

a) A abordagem reducionista pressupõe a subdivisão do objeto de estudo em seus vários componentes ou partes, a fim de se compreender o seu todo, como ocorre frequentemente nas ciências exatas, tais como a Física, a Química, a Biologia e outras. b) Na abordagem sistêmica a premissa básica é que 'o todo é mais do que a soma de suas partes' e que o comportamento e a construção das partes são ambos moldados pela estrutura do próprio sistema (BUZAN, 1995).

Analisando as correntes do Realismo Clássico, Maquiavel (1997) permite perceber que a relação entre os Estados é desordenada, o que refletiria nas sociedades. Seguindo esse raciocínio, existe uma preocupação com a segurança e independência, à medida que as grandes Nações querem dominar as pequenas. Acrescentando, Hobbes (2000) identifica o estado natural das relações internacionais com o da guerra, por não existir contrato social entre os países que os submeta a algum soberano ou instituição internacional.

Todavia, ao observar as mudanças na história das relações entre os países, percebe-se um desenvolvimento das instituições internacionais e o aprofundamento das relações externas. Em um nível de análise, Singer (1960) caracteriza o sistema internacional,

\footnotetext{
${ }^{12}$ Fronteira da paz: Termo que abrange as cidades de Rivera e Santana do Livramento, fronteira Uruguai-Brasil. Este nome é um resultado da cultura de integração surgida da convivência internacional pacífica de ambos povos.
} 
considerando padrões de comportamento e níveis de interdependência entre os Estados. Ainda, o Estado-Nação possui processos domésticos que afetam as decisões da política externa.

Quando a política externa de um país é analisada, deve-se distinguir a política do Estado e a política de governo. O Estado-Nação possui, por meio da tradição, de suas atuações e tomadas de decisão, certa identidade internacional. É o caso do Ministério das Relações e do Itamaraty. Eventualmente, o governo em gestão pode tomar medidas que fogem ao habitual, ações externas diferentes de interesse percebido.

As mudanças no sistema internacional trouxeram uma necessidade de adequação aos preceitos da teoria clássica, configurando a vertente neorrealista. Essa tradição passou a dominar o debate das relações internacionais, por apresentar interpretações pertinentes e críticas contundentes. Para Baldwin (1993), mantém-se uma concordância quanto à natureza anárquica do sistema internacional, mas há desacordos no que diz respeito ao significado do sistema anárquico. Também é necessário analisar como um grupo de fatores influencia os agentes internacionais, como os ganhos absolutos e relativos, e a importância da cooperação para a manutenção do poder.

Na década de 80, o analista internacional Nye (2004) conceitua e propõe a compreensão do exercício do poder, de um Estado em outro, por Hard Power e Soft Power. Assim, o Hard Power refere-se ao poder nacional que vem por meios militares e econômicos, enquanto que o Soft Power refere-se à habilidade em influenciar indiretamente o comportamento, ou interesses, de outros corpos políticos por meios ideológicos ou culturais.

Por sua natureza cientifica, a própria teoria das Relações Internacionais chama a atenção para uma importância de estudar cultura. Tal necessidade é naturalmente reconhecida pelos agentes diplomáticos, por mais que o campo literário não a aborde de forma mais específica:

\footnotetext{
Ainda que não faltassem textos sobre políticas culturais em nosso país, raros eram aqueles que se dedicavam à projeção externa desse trabalho como fator relevante de nossa presença internacional, e nenhum, até então, se dedicara a apresentar o tema de forma mais sistematizada - muito embora o Itamaraty se destacasse, havia gerações como instituição dedicada à divulgação de nossa cultura no exterior. No Ministério, a importância do assunto era naturalmente reconhecida, mas até em nosso meio inexistiam estudos ou ensaios de inspiração acadêmica que de alguma forma tentassem comprovar a relevância dessa vertente de nossa atuação diplomática. Outros países (e outras diplomacias) se ressentiam do mesmo problema. Tanto que, na época, era modesta a bibliografia básica que permitisse traduzir em palavras o que todos nós, da carreira, intuitivamente sentíamos. (RIBEIRO, E., 2011)
} 
Percebe-se que a cultura possui um papel fundamental dentro das Teorias das Relações Internacionais. Seu conceito está intimamente presente na compreensão dos indivíduos, dos Estados e, logo, do sistema internacional. Fatores políticos, econômicos, sociais e ambientais estão diretamente associados ao seu conceito. Atributo vital da diplomacia e da paradiplomacia.

De acordo com Rubim (2013), as gestões dos ministros de cultura Gilberto Gil e Juca Ferreira trouxeram ao Brasil um novo patamar de políticas culturais, depois de evidenciar e revisar as tristes tradições das políticas públicas para esta área. Desde a criação do Ministério da Cultura, em 1985, "não implicou uma descentralização e nacionalização dos equipamentos e, por conseguinte, da atuação do órgão. Ele continuou sendo um ministério que opera de modo muito localizado e desigual".

A existência de uma tradição autoritária e de políticas culturais nacionais impossibilitaram que estas pudessem ser discutidas e negociadas com a sociedade civil, em especial com os setores interessados em cultura. Consequentemente, isso impossibilitou a criação de políticas públicas de cultura com qualidade:

"(...) políticas que podem emanar do governo, mas que, submetidas ao crivo do debate crítico e da deliberação com a sociedade civil, se transformam em políticas públicas de cultura. Tais políticas, dado seu caráter democrático e pactuado, retêm mais possibilidade de transcender esta comprometedora tradição de instabilidade." (RUBIM, 2013)

Contudo, as políticas culturais demandam a necessidade de projetos de Estados, e não somente de governos. São ações estratégicas que demandam ações a curto, médio e longo prazo.

\section{Paradiplomacia}

\subsection{Breve Desenvolvimento Histórico}

Tradicionalmente, o processo de formação e aplicação das políticas públicas externas é basicamente um processo de decisão nacional, onde o governo nacional, por meio do Ministério de Relações Exteriores ${ }^{13}$, exerce e possui responsabilidades dentro do sistema internacional.

\footnotetext{
${ }^{13}$ No Brasil, o Palácio Itamaraty, também conhecido como Palácio dos Arcos, é a sede do Ministério das Relações Exteriores.
} 
Historicamente, as relações entre Estados são geridas pelos seus governos centrais. Arte tradicionalmente conhecida como a diplomacia, é constituída pela Administração Pública e do Serviço Diplomático de um Estado nacional (NICOLSON, 1955). Os EstadosNação eram considerados, tendo em vista a soberania estatal, os únicos atores com personalidade internacional que poderiam elaborar tratados e celebrar acordos.

Com o final da Guerra Fria ${ }^{14}$, outros novos atores ganham ênfase neste cenário. A multipolaridade nas relações econômicas e comerciais entre os Estados, em conjunto com a unipolaridade militar, cria uma reestruturação no sistema internacional. As Relações Internacionais vivem em constante mudança. Novos agentes com personalidade internacional e agentes subnacionais ganham força para operar fora da lógica única de influência e troca de interesses entre governos de Estados Nacionais. Até dado momento, a tarefa da dinâmica de inserção internacional era atribuição exclusiva da governança.

Com o desenvolvimento da globalização, surgem novas dificuldades, novos conflitos, e cada vez mais o Estado nacional atribui responsabilidades às instâncias subnacionais e flexibiliza papéis e atribuições, o que faz com que o poder seja direcionado aos agentes subnacionais para que haja uma melhor eficácia em resolver todas essas novas questões. (MOREIRA, SENHORAS E VITTE, 2009,p. 3)

A evolução da tecnologia proporciona ambiente para os fenômenos transnacionais, cosmopolitas e o entendimento de aldeia global. Neste cenário, os indivíduos, como atores internacionais, não recebem personalidade jurídica internacional, mas começam a participar nas tomadas de decisão.

\subsection{A parodiplomacia na atualidade}

No século XX, o conceito de diplomacia encontra uma nova complexidade. A globalização ${ }^{15}$, com seus fenômenos da comunicação e transporte, traz mudanças no campo da economia, tecnologia e sócio-política. O leque de atividades do campo diplomático ganha

\footnotetext{
${ }^{14}$ Em 1989, a queda do muro de Berlim simboliza o encerramento de décadas de disputas econômicas, ideológicas e militares entre o bloco capitalista (Estados Unidos) e o socialista (União das Repúblicas Socialistas Soviéticas - URSS).

${ }^{15}$ Os acadêmicos divergem sobre uma conceituação dos fenômenos da globalização. Justamente por se tratar de fenômenos espontâneo, decorrente da evolução do mercado capitalista, que levam a interconectividade do mundo. Não possuindo um direcionamento de entidade ou individuo. Possui várias linhas teóricas que explicam como ocorreu e seus efeitos no mundo. Adotaremos aqui a noção de Stuart Hall (2003), de que a globalização alteraria as noções do tempo e do espaço, desaloja o sistema social e as estruturas - que por muito tempo foram consideradas como fixas - e possibilitaria o surgimento de uma pluralização dos centros de exercício do poder. Outros autores também são referência do assunto, dentro das Relações Internacionais: Samuel P. Huntington, Boaventura Souza Santos, Hardt e Negri
} 
novas abrangências, existindo novas necessidades e exigindo mais dinamismo para as soluções. O sistema internacional opera em um mundo mais veloz e com menores distâncias.

Na contemporaneidade, o desenvolvimento econômico e social em diversos pontos globais fomentou o crescimento da internacionalização do público e do privado. Muitas empresas, municípios, regiões e estados federais ganham importância e relevância na agenda da política externa do governo central, seja por desenvolvimento ou por segurança da soberania. Concomitantemente, existe o aumento da fiscalização dos assuntos internacionais por parte dos agentes subnacionais. "A política exterior também é cada vez mais segmentada tanto funcionalmente, entre os diversos ministérios, como territorialmente, envolvendo as unidades não centrais" (SOLDATOS, 1990, p. 36).

Assim como os efeitos da globalização econômica trouxeram atores empresariais ao nível de transnacionais ${ }^{16}$, a instituição governamental também se reconstrói diante daquilo que ela também estimula. Existe uma dinâmica muito orgânica na internacionalização dos Estados e suas economias, que possui influências na necessidade de aprimorar também cada subdivisão administrativa de suas instâncias.

As oportunidades e o desenvolvimento estão cada vez mais vinculados à capacidade de um Estado-Nação especializar cada área de sua gestão, em detrimento de fortificar uma centralidade lenta e distante das situações emergentes. Utiliza-se do diálogo e da cooperação como principal ferramenta de informação.

De acordo com Santana (2009), a paradiplomacia tem como característica fundamental a cooperação. As cidades, por exemplo, trocam muitas informações entre si. Seja no urbanismo, no saneamento, na infraestrutura ou nas habitações. O autor também relata que as políticas públicas geralmente buscam solucionar a pobreza e a violência. É também comum a aproximação da sociedade civil, pela população, com o poder público na formulação de políticas de acordo com as demandas. "Os entes subnacionais, com seus tentáculos e ramificações, vão onde os governos centrais não conseguem alcançar, quebrando o distanciamento entre apolítica externa e os reais anseios da população" (SANTANA, 2009, p.42).

A Cooperação Internacional descentralizada auxilia na construção da imagem e da inserção internacional dos estados federais e dos municípios, promovendo-os de forma direta e indireta, no público e no privado, visando resultados socioeconômicos ou políticos. Ainda, auxilia na regulação das desigualdades regionais, trazendo benefícios ao Estado Nacional.

\footnotetext{
${ }^{16}$ Multinacionais são corporações que atuam em distintos territórios. Possuem sua matriz em um determinado país, mas ultrapassam os limites territoriais na sua atuação.
} 
Pode-se considerar a paradiplomacia como uma das formas de descentralização na gestão das relações internacionais. Aspectos importantes da política exterior assumem dimensões locais e internas, e ao mesmo tempo aspectos da política interna assumem cada vez mais dimensões internacionais. (DIAS, 2010, p.2)

A diplomacia relaciona-se com a implementação técnica dos planos da agenda de política externa dos Estados. A paradiplomacia, por sua vez, é muito mais abrangente, evolvendo todo um conjunto de atividades externas dos entes subnacionais e também dos não governamentais.

Para entender melhor as áreas de competência, o autor Wirtz (2007) ressalta a diferença entre High politics e Low politics. A primeira está relacionada com o interesse primário do Estado, segurança nacional e segurança internacional, como por exemplo: questões de guerra e paz, dissuasão nuclear, controlam de armamentos, alianças militares, defesa. Em contrapartida, Low politics não são encaradas como ameaças ou riscos para a segurança, podendo as subestatais (no caso brasileiro, os estados e municípios) conduzir essas segundas políticas no âmbito local: da economia, intercâmbio cultural, meio ambiente, turismo e outros assunto.

De acordo com Aguirre (1999), o termo paradiplomacia surge a partir de um debate acadêmico ocorrido no final da década 1970, em um contexto das discussões sobre o Novo federalismo.

Os primeiros a utilizar o termo paradiplomacia foram os professores Ivo Duchacek, da Universidade da Cidade de Nova York, e Panayotis Soldatos, das Universidades de Paris e Livre de Bruxelas, sendo considerados os pioneiros no uso do vocábulo. Para esses dois autores, a paradiplomacia consiste nos contatos, atividades, processos e iniciativas externas entre governos não centrais (estados federados, províncias, cantões etc.) e outros atores internacionais, como os Estados-nação, outros governos locais, empresas privadas, organizações internacionais, organizações não governamentais internacionais entre outros. Constituem atividades que não conflitam com as atividades de política exteriores executadas pelos órgãos diplomáticos dos Estados nacionais, pois esta é uma atribuição exclusiva do governo central (da União, no caso brasileiro). As ações da paradiplomacia complementam e apóiam a ação diplomática estatal, o que indica o sufixo "para" que significa "paralelo". Assim a paradiplomacia ocorre paralelamente às ações de política exterior dos Estados, não conflitando com estas. $\mathrm{Na}$ realidade as ações internacionais dos governos subnacionais, no contexto paradiplomático, complementa e amplia a ação diplomática tradicional. (DIAS, 2010, p.2)

De acordo com Soldatos (1990), consideram-se como paradiplomáticas as atividades externas dos governos subnacionais quando existem elementos de política exterior e atores que executem essas políticas. Por consequente, os governos não centrais possuem considerável autonomia para formular e programar os objetivos de suas agendas. 
Contudo, a simples instrumentalização destes agentes nas decisões do governo central não pode ser considerada paradiplomática. A noção de paradiplomacia não diz respeito à delegação ou subcontratação dos governos locais.

A paradiplomacia pode ser definida como o envolvimento de governo subnacional nas relações internacionais, por meio do estabelecimento de contatos, formais e informais, permanentes ou provisórios ('ad hoc'), com entidades estrangeiras públicas ou privadas, objetivando promover resultados socioeconômicos ou políticos, bem como qualquer outra dimensão externa de sua própria competência constitucional. Embora bastante contestado, o conceito de paradiplomacia não impossibilita a existência de outras formas de participação subnacional no processo da política externa, mais diretamente ligado ao departamento de relações exteriores de governos centrais, como a assim chamada diplomacia federativa, tampouco impede o papel cada vez maior dos governos subnacionais nas estruturas de multicamadas para a governança regional ou mundial. (PRIETO, 2004)

Para Dias (2010), a paradiplomacia não pode existir sem uma estrutura de relações trilaterais, que envolvam o governo central, a governança local e atores estrangeiros. As ações são implementadas com a cooperação destes agentes. A natureza paradiplomática é descrita através desta inter-relação entre atores.

\section{Cultura e Interculturalidade na paradiplomacia}

O presente artigo, concomitante com o entendimento da paradiplomacia e de suas atuações, procura debater a importância da cultura para as relações internacionais com uma fundamentação teórica. O estudo conceitual sobre cultura é fundamental para as Ciências Humanas, como as Relações Internacionais.

$\mathrm{Na}$ sociedade acadêmica, é cada vez mais perceptível a valorização da diversidade cultural, democraticamente sendo o melhor direcionamento para conduzir os processos sociopolíticos entre indivíduos, instituições, países e no sistema internacional. Oportunamente, os atores que fundamentam as relações transnacionais.

Tanto para a interação entre os povos, quanto para as relações bilaterais dos países, a valorização da heterogeneidade é de suma importância. Segundo Ribeiro, A. (2008), para existirem relações solidamente estruturadas e compreensão mútua, não é suficiente a valorização da diversidade de maneira superficial, por uma mera coabitação multicultural.

A relevância do entendimento cultural se faz evidente na compreensão de vários elementos particulares, como os processos históricos que permitem o desenvolvimento de costumes, tradições, modas, mitos e ritos. O próprio Direito Internacional Público é baseado 
em um Direito Consuetudinário ${ }^{17}$. Evidencia-se, assim, a importância dos estudos sobre cultura para o maior entendimento dos fenômenos que permitem perceber o funcionamento das inúmeras sociedades no âmbito internacional.

A interculturalidade no sistema internacional funciona como fator de união das diversas estâncias. Ela permite o diálogo entre dois elementos de distintas culturas. Ribeiro, A. (2008) ainda acrescenta que este fenômeno existe há muito tempo, com épocas de maior abertura ou violência. Tais argumentos deixam claro que a cultura possui papel destacado nas Relações Internacionais.

Por si só, a Interculturalidade não resolve parte substancial dos problemas do confronto entre culturas, povos e regiões. Os problemas políticos têm de ser resolvidos nas estâncias políticas, tal como os econômicos. A cultura apenas pode estabelecer pontes. A Interculturalidade não supõe uma perfeição total, que somos todos iguais e gostamos todos muito do Outro (RIBEIRO, A., 2008).

A valorização e compreensão da heterogeneidade cultural são os fatores principais para entender a diversidade das relações humanas. Por conseguinte, a diversidade cultural:

(...) é o reconhecimento de conteúdos e costumes culturais e pré-dados; mantida em um enquadramento temporal relativista, ela dá origem a noções liberais de multiculturalismo, de intercâmbio cultural ou da cultura da humanidade. [...] A diversidade cultural pode inclusive emergir como um sistema de articulação e intercâmbio de signos culturais em certos relatos antropológicos do início do estruturalismo (BHABHA, 1998).

As culturas não permanecem limitadas às esferas físicas demarcadas, geográficas, territoriais, elas transbordam as fronteiras (APPADURAI, 2004). Os indivíduos que vivem em uma área de fronteira percebem o outro, ou seja, os indivíduos de outra nacionalidade, quando ultrapassam as suas fronteiras ou quando possuem sua fronteira transpassada. Se o sujeitos produzem o local, e a localidade é produzida pelos sujeitos, então, cada indivíduo determina sua subjetividade e sua localidade. Estes elementos são determinados não só porque os cidadãos se deslocam fisicamente, mas também porque captam o que se move, mesmo que estejam parados. (APPADURAI, 2009)

As cidades de fronteira estabelecem relações umas com as outras, buscando objetivos e necessidades em comum, em várias áreas de vantagens. É o caso de algumas cidades fronteiriças do MERCOSUL, que estabelecem acordos e negociações. Por mais que não sejam diplomatas, os profissionais que trabalham com a paradiplomacia, muitas vezes, atuam de maneira semelhante. As governanças locais, ao exercer relações paradiplomáticas, possuem maior qualidade para identificar necessidades e informações da localidade.

\footnotetext{
${ }^{17}$ Direito baseado nos costumes.
} 
Para Ribeiro, A. (2008) as comunidades e pessoas necessariamente passam por uma readaptação ao conviver com a produção de componentes que possuem origem em outros locais. Concomitantemente, existe também a movimentação humana, não somente a de mercadorias. A necessidade do trabalho, tanto para o sofisticado intelectual ou o proletário mais humilde, leva as pessoas a migrar, frequentemente mais de uma vez. (APPADURAI, 1997)

Para Appadurai (1997), as zonas de fronteira estão se transformando em espaços de complexa circulação, quase legal, de pessoas e mercadorias. Todas as zonas de livre-comércio são, de alguma forma, translocalidades. Estas aparecem sob várias formas, enquanto uma categoria emergente de organização humana, e exigem muita atenção, visto que podem substantivamente divorciar-se de seus contextos nacionais, como por exemplo:

\begin{abstract}
Estas cidades dividem-se em dois tipos: os principais centros econômicos tão profundamente envolvidos em comércio, finanças, diplomacia e mídia internacionais que se tornaram ilhas culturais com referências nacionais muito frágeis: Hong-Kong, Vancouver e Bruxelas são exemplos desse tipo de cidade. Quer por processos econômicos globais que ligam essas cidades entre si mais do que com seu país, quer por guerras civis implosivas de origem transnacional, outras cidades transformam-se em translocalidades fragilmente conectadas ao interior de seu país: Sarajevo, Beirute, Belfast e Mogadício são exemplos desse segundo tipo. (APPADURAI, 1997, p.49)
\end{abstract}

Os sucessivos conflitos entre Brasil e seus vizinhos platinos delimitaram as fronteiras do Rio Grande do Sul com o Uruguai. Para Moreira (2003), referenciado por Freitas: "(...) são áreas nas quais sempre predominou a preocupação com a preservação e a defesa e que por isso marcam de modo concerto a separação entre o território brasileiro e o dos vizinhos" (MOREIRA, 2003, p.8) ${ }^{18}$. Com a criação do MERCOSUL, as fronteiras se tornaram espaço de pretendida integração e fluxo de produtos, bens e pessoas.

\title{
6 Conclusão
}

Existem diversos fatores que explicam a importância da paradiplomacia. Assim como existem várias situações que evidenciam a necessidade de se valorizar a cultura como política pública, e que finalmente irá se tornar instrumento catalisador de ações diplomáticas subnacionais.

\footnotetext{
${ }^{18}$ Cibele B. Figueiredo Freitas, Estudo do Espaço Fronteiriço na obra "Uma terra só", de Aldyr Garcia Schlee. Disponível em <http://www.celpcyro.org.br/joomla/index.php?option=com_content\&view=article\&Itemid=0\&id=540>. Acesso em: 16 de novembro de 2014.
} 
As ações paradiplomáticas existem a partir das mais distintas iniciativas e com os mais diversos países. Mas certamente, deve-se dar uma maior atenção aos vizinhos que estão ao redor do país, por questões lógicas e estratégicas da geopolítica.

Da globalização, surgiram os crescentes fomentos para transformações técnicas e econômicas. Então, a democratização do poder estatal permitiu o aparecimento de novos atores, agentes subnacionais no contexto da paradiplomacia. Isso vem a ocorrer com o objetivo de expandir a participação internacional, afinal estamos em um cenário mundial globalizado, cosmopolita e interdependente.

Nesta direção, a concepção tradicional de um Estado com poderes soberanos indivisíveis acaba cedendo espaço para a introdução de novas personalidades, capazes de celebrar acordos e realizar ações na condução de uma política internacional. A integração regional foi fortalecida à medida que as fronteiras foram rompidas, dando visibilidade maior para atores subnacionais, como: municípios, estados federativos, províncias, entre outros. É importante lembrar que esses, todavia, são sujeitos sem personalidade jurídica internacional.

Ainda que os atores subnacionais não gozem de plenos atributos jurídicos, parecem irreversíveis os processos pelos quais estes começam a passar. A criação de contatos entre os governos não centrais aumenta a dinâmica necessária para o desenvolvimento de acordos, nos mais diversos setores. Desta forma, a prática da paradiplomacia é acentuada no contexto internacional, com maior desenvolvimento das tecnologias de informação e meios de comunicação.

O presente século também permitiu uma maior compreensão do estudo conceitual sobre Cultura. Estas percepções possibilitaram maior sensibilidade para a heterogeneidade e diversidade cultural. Entendimento este de suma importância para a realização da diplomacia e para o estudo e aplicação das Teorias de Relações Internacionais.

A compreensão cultural, dentro dos estudos das Relações Internacionais, torna-se mais evidente com as constantes transformações que o planeta vem sofrendo, através dos imperativos dos fenômenos globais. Os fatores de produção e consumismo geram maior ligação entre os indivíduos de diferentes localidades. A interdependência dos Estados, a noção de aldeia global e o cosmopolitismo demonstram uma outra forma de observar as limitações dos modelos centrados na figura do Estado-Nação.

Desde os tempos mais antigos, os governantes possuíam representações oficiais para dialogar e desenvolver ações com outros povos. Nas atuais formas de governo, ainda continua o emprego de agentes oficiais, como na diplomacia. De fato, esta é a melhor forma de manter 
a legitimidade e segurança dos interesses oficiais das democracias adquiridas e, ainda, a soberania estatal.

A tecnologia atual permite aos Estados protegerem melhor sua soberania, tanto no que diz respeito a suas fronteiras quanto ao controle de quem e quantos indivíduos transpassam o seu território. Contudo, a quantidade de pessoas que existe hoje, no mundo, e o aumento nos fluxos migratórios dificultam o controle governamental. Ainda mais em países de grande dimensões como o Brasil, com fronteiras com 10 países vizinhos.

Se proteger e contabilizar já é uma tarefa extremamente difícil, desenvolver estas regiões e cidades é algo ainda mais árduo. Concomitantemente com o fato de que nestas situações em especial, o governo não é detentor de toda a autoridade, ele deve compartilhar suas ações com o governo do Estado vizinho, ou governos, no caso de relações trilaterais ou multilaterais.

A existência de um poder centralizado, longe do cotidiano das localidades fronteiriças, pode não usufruir de completa capacidade e qualidade de gerir estas regiões. Evidencia-se, novamente, a necessidade da paradiplomacia nestes contextos. Nas regiões de fronteira, os atores subnacionais, não centrais, universidades e a sociedade civil, possuem uma experiência de causa vivida diariamente. Conhecimentos que fazem parte intrínseca da Cultura destes agentes e que ultrapassam a temporalidade das gestões governamentais.

Assim, o desenvolvimento da paradiplomacia, juntamente com uma importância pública para questões de Cultura e um maior espaço para a participação de novos atores, pode ser a chave para o fortalecimento da zona fronteiriça do Brasil e Uruguai e para a cooperação em políticas públicas.

Tal zona fronteiriça, por toda uma questão da formação histórica, política e cultura, demonstra-se um excelente laboratório para a implementação de ações paradiplomáticas. Enquanto são percebidos conflitos em várias fronteiras pelo mundo, essa fronteira é um exemplo de que podem existir cooperação e desenvolvimento, onde uma vez havia a rivalidade e a disputa territorial.

\section{Referências}

ACHUGAR, Hugo. Planetas sem Boca. Belo Horizonte: Ed. UFMG, 2006.

AGUIRRE, I. Making sense of Paradiplomacy? An Intertextual Inquiry about a Concept in Search of a Definition . In: Aldecou, F. and Keating, M.(Eds.) Paradiplomacy in Action: the foreign relations of subnational governments. London/Portland, OR: Frank Class, 1999. 
APPADURAI, ARJUN. Soberania sem territorialidade: notas para uma geografia pós nacional. Novos Estudos Cebrap, n.49, 1997.

APPADURAI, Arjun. Dimensões culturais da globalização: a modernidade sem peias. Lisboa: Teorema, 2004. 304p.

BALDWIN, David A. "Neoliberalism, Neorealism, And World Politics". David A. Baldwin (ed.): Neorealism and neoliberalism: the contemporary debate (New York: Columbia University Press, 1993), pp.3-28.)

DIAS, Reinaldo. Um tema emergente nas Relações Internacionais: A paradiplomacia das cidades e municípios. In: Âmbito Jurídico, Rio Grande, XIII, n. 79, ago 2010. Disponível em:

<http://www.ambitojuridico.com.br/site/index.php?n_link=revista_artigos_leitura\&artigo_id= 8156>. Acesso em 05 de outubro de 2014.

DUCHACEK, Ivo. Perforated Sovereignties: Towards a Typology of New Actors in International Relations. In: Federalism and International Relations: the role of subnational units/ Ed: Hans MICHELMANN \&Panayotis SOLDATOS. Oxford: Claredon Press, 1990, p. $1-33$.

Federação Nacional dos Estudantes de Relações Internacionais: Disponível em: <http://www.feneri.org.br/feneri/faculdades>. Acesso em: 05 de outubro de 2014.

FREITAS, Cibele B. Figueiredo Freitas, Publicação: Estudo do Espaço Fronteiriço na obra "Uma terra só", de Aldyr Garcia Schlee. Disponível em

$<$ http://www.celpcyro.org.br/joomla/index.php?option=com_content\&view=article\&Itemid=0 $\& \mathrm{id}=540>$. Acesso em: 16 de novembro de 2014.

Governo do Estado do Rio Grande do Sul - Gabinete do Governador - Assessoria de Cooperação e Relações Internacionais, Entrevista: Assessor fala sobre desdobramentos do Plano de Fronteira RS. Disponível em <http://www.relinter.rs.gov.br/conteudo/1197/?Entrevista\%3A_assessor_fala_sobre_desdobra mentos_do_Plano_de_Fronteira_RS >. Acesso em: 19 de novembro de 2014

Governo Municipal de Bagé, Matéria: Governo Brasileiro aprova projeto de Valorização do Patrimônio Cultural de Bagé.

http://www.bage.rs.gov.br/noticias_visualiza.php?id=1570>. Acesso em: 19 de novembro de 2014.

GUIMARÃES, Lytton L. Relações Internacionais como Campo de Estudo. Cadernos da REL. Brasília: UnB, 2001.

HALL, stuart. A Identidade Cultural Na Pós-Modernidade. 7.ED. RIO DE JANEIRO: DP\&Z, 2003.

HOBBES, T. Leviatã. São Paulo: Ícone, 2000, p. 95.)

KANT Immanuel. À paz perpétua. Trad. Sod a direção de Marco Zingano. Porto Alegre: LP\&M, 2008. 
IBGE, Disponível em:

<http://www.ibge.gov.br/home/geociencias/geografia/fronteira.shtm?c=3>. Acesso em: 25 de outubro de 2014.

Manifesto Cultural da Fronteira Brasil-Uruguai. Disponível em:

$<$ http://primaveracomdilma.cc/manifesto-cultural-da-fronteira-brasil-uruguai/> Acesso em: 15 de outubro de 2014.

Ministério das Relações Exteriores - Agência Brasileira de Cooperação. Disponível em <http://www.abc.gov.br/>. Acesso em: 19 de novembro de 2014

MAQUIAVEL, N. O príncipe. São Paula: Revista dos Tribunais, 1997, p. 81.)

MCLUHAN, Marshall. Os meios de comunicação como extensão do homem. São Paulo. Cultrix,1964.

MINIUCI, Geraldo. Diplomacia federativa. São Paulo: mimeo, 2004.

MOREIRA, F de A; SENHORAS, E. M.; VITTE, C. de C. S. Geopolítica da Paradiplomacia Subnacional: um estudo sobre a extroversão internacional dos municípios da rede de Mercocidades. Disponível em

<http://works.bepress.com/cgi/viewcontent. cgi?article=1121\&context=eloi>. Acesso em: 05 de novembro de 2014.

MOREIRA, Maria Eunice. Portugueses e castelhanos na literatura sul-rio-grandense.

Boletim - Revistada Associação Internacional de Leitura - Conselho Brasil Sul, nº 1-4, 1989.

NICOLSON, Harold. La diplomacia. México: FCE, 1955.

NYE, Joseph S. Soft Power: The Means to Success in World Politics. New York : Public Affairs, 2004.

PRIETO, Noé Cornago. O outro lado do novo regionalismo pós-soviético e da ásiapacífico. In: VIGEVANI, Tullo (Org.). A dimensão subnacional e as relações internacionais. São Paulo: Unesp, 2004, p. 252-252

RIBEIRO, Antônio. Construir com o outro: A diversidade está naturalmente a misturarse. 2008. Disponível em: < http://www.snpcultura.org/vol_construir_com_outro.html>. Acesso em: 16 de novembro de 2015.

RIBEIRO, Edgard Telles. Diplomacia Cultural: Seu Papel na Política Externa Brasileira. Fundação Alexandre Gusmão. Brasília, 2011. Disponível em: < http://funag.gov.br/loja/download/824-Diplomacia_Cultural__Seu_papel_na_PolItica_Externa_Brasileira_2011.pdf>. Acesso em: 17 de novembro de 2015.

SCHLEE, Aldyr Garcia. Uma terra só. São Paulo: Melhoramentos, 1984.

SINGER, J. David. Review: International Conflict: Three Levels of Analysis, World Politics, Vol. 12, No. 3. (Apr., 1960), pp. 453-461. 
SINGER, J. David. The Level-of-Analysis Problem in International Relations, World Politics, Vol. 14, No. 1, The International System: Theoretical Essays. (Oct., 1961), pp. 77 92.

SOLDATOS, P. An Explanatory Framework for the Study of Federal States as Foreignpolicy Actors. In: Michelmann, H.J. and Soldatos, P. (Eds.) Federalism and International Relations: the role of subnational units. Oxford: Claredon Press, 1990. Pp. 34-53 ROUSSEAU, Jean-Jacques. Do contrato social. São Paulo: Abril Cultural, 1978.

RUBIM, Antonio Albino Canelas. Políticas culturais do Governo Lula / Gil: desafios e enfrentamentos. Salvador, 2007. Disponível em

<http://estudosculturais.com/revistalusofona/index.php/rlec/article/download/17/43>. Acesso em: 29 de novembro de 2014.

TELES, Reinaldo; PIERI, Vitor Stuart de; OLIVEIRA, Fabiana. O debate do turismo na paradiplomacia: o caso da Mercocidades. In: Teles, Reinaldo \& Pieri, Vitor Stuart de (Orgs.). Turismo e Paradiplomacia das cidades: o local no diálogo com o global. Rio de Janeiro: Cenegri, 2014.

WALTZ, Kenneth N. O Homem, o Estado e a Guerra: uma análise teórica. São Paulo: Martins Fontes, 2004, 331p

WALTZ, Kenneth N. Theory of International Politics. New York: McGraw Hill, 1979.

WIRTZ, James (2007). A New Agenda for Security and Strategy? in BAYLIS, John [et al.].Strategy in the Contemporary World.Second edition. Oxford: Oxford University Press: 337-355 